\title{
Table-top Exercises for Emergency Management: Tame Solutions for Wicked Problems
}

\author{
Svante Edzén \\ Luleå University of Technology \\ svante.edzen@1tu.se
}

\begin{abstract}
In response to large emergencies, emergency managers deal with unknown situations characterized by complexity and uncertainty, so-called wicked problems. Existing tabletop exercises are used to train, test and exercise emergency managers but do table top exercises mirror the wickedness? A pilot study where emergency managers were interviewed about the use of tabletop exercises has been carried out. The pilot study and traditional tabletop exercises are analyzed through the lens of wicked problems. The result shows that tabletop exercises partly mirrors wicked problems but cannot handle every aspect of wicked problems. The main reasons for this are, that the planning of tabletop exercises in which the problems and solutions are known beforehand tames the problems and that focusing on the use of plans entails leaving unplanned problems unaddressed. I propose three design ideas to be used when designing tabletop exercises to better prepare emergency managers for wicked problems. First, focus on unsolved (wicked) problems instead of on problems already handled in plans and allow participants to identify them. Second, let participants tame the problems during the exercise instead of taming the problems ahead of time planning the exercises. Third, use existing plans and lessons learned from previous emergencies, and resolve the problems in collaboration.
\end{abstract}

\section{Introduction}

The aim of this work is to find design ideas as a foundation for developing an Internet-based tool for tabletop exercises. The study focuses on the management level at the command center where responses to emergencies are managed. Tabletop exercises are used for preparing emergency managers to respond during large-scale societal emergency situation. Several emergencies have the characteristics of wicked problems (uncertain, complex, and having no obvious solution) as opposed to tame problems (simple or complex but having possible-to-define solutions) [2]. For all such emergencies several agencies participate in the response activities. Each of these has an emergency manager and one of these managers is appointed responsible for the entire operation as the incident commander. The incident commander's task is to be coordinate several agencies and other stakeholders with different capabilities in order to create a temporary dynamic organization that can adapt to dynamic, unique and uncertain emergency situations [1]. Incident commanders and emergency managers face situations that differ depending on the scale and type of emergencies ranging from everyday responses to larger response operations. Car fires, traffic accidents, and residential fires are examples of everyday responses. These problems are characterized by a consensus regarding the problem's definition and perhaps also its solution; they are called tame problems [9]. In larger response operations gaining an overview of the situation is challenging because of increased complexity and uncertainty, because several agencies and other stakeholders are involved in the response action, and because the situation as a whole is difficult or impossible to plan for. Responses to emergencies like train accidents, and forest fires entail such operations. These are examples of wicked problems characterized by lack of agreement on the problem's definition and its solution [9]. The situation is compounded if the emergency develops into a crisis or worse a disaster, that is, if the extent of the accident increases to affect more people or a larger geographic area and involves major personal or property damage.

Emergency management consists of four phases; mitigation, preparation, response, and recovery. This work concerns the preparation phase, during which emergency managers prepare to deal with emergencies in the response phase. Preparation takes place in the emergency-planning process which is a planningtraining-exercise process. In the planning stage the knowledge, skills, resources, and abilities that are likely to be needed for a given response are documented in a plan. From such plans it is possible to identify the deeded knowledge, skills, and resources to design training that fulfills those needs. Exercises can then use simulated accidents to test the overall capacity 
of the agency, as well as to test individuals' knowledge and skills [3]. Planning for emergencies is a difficult task, and the difficulties increase significantly when the complexity and uncertainty of the emergency increases [4] that is, when the situation's wickedness intensifies. Some problems are tame and some are wicked, but organizations must prepare to manage all types of problems. This implies that this wickedness should also be reflected in exercises. The question to be answered here is this: Do tabletop exercises mirror wicked problems?

A number of authors agree on that managing of emergencies are examples of wicked societal problems, and many have done studies in the field. Stubbard [2] argues that crisis or emergency decisions are mainly non-routine or wicked problems and are characterized by uncertainty, complexity, conflicting interests, and ego involvement. The article discusses ways to handle decision making in crises and conclude that there is no grand unifying framework for crisis response. Turoff [5] provides an overview of emergency preparedness and management and discusses relevant theories - for example, high reliability organizations and muddling through - and recommends to promoting more effective planning, management, and response. Muddling through is an approach using incremental changes based on an understanding of the past that is, using solutions devised for similar problems and adjusting them to the current situation [6]. O'Brien [7] argues that responding to wicked problems requires greater emphasis on pre-disaster planning driven by social learning processes in which there is a need to consider the perceptions and understanding of all the parties that might be involved. Plotnick [8] proposes a model of an individual's cognitive responses to threat and reviews system-design principles that can support flexible, adaptive responses in a crisis. An approach for resolving general wicked problems is proposed by Roberts [9], who describes three context dependent strategies (competitive, authoritative, and collaborative approaches) for coping with wicked problems. Huthinson [20] suggests a team-based approach to planning for and solving wicked problems. A team consists of individuals who have knowledge relevant to every aspects of the problem. This approach can be seen as an implementation of the collaborative approach. Conklin [10] argues that addressing wicked problem is a process in which problem solving and learning are tightly intertwined and that the flow of this learning process is opportunity driven.

However, as far as I know, no one has investigated the way these theories, models, and strategies can be applied in tabletop exercises. The contribution of this work is to apply these approaches in order to create ideas guiding the design of tabletop exercises that will better prepare emergency managers to effectively face wicked problems.

The rest of the paper is structured as follows: section 2 Research Process, 3 Wicked Problems and Emergencies, 4 Tabletop Exercises, 5 The Pilot Case, 6 Design Ideas, and ending with section 7 Discussion.

\section{Research Process}

This article is part of a design research [11] project in which the overall objective is to develop an Internetbased tabletop exercise planning and training tool that improves managers' preparedness to handle problems with inter-organizational aspects in emergency situations. In order to accomplish this, I need to identify existing problems and areas of improvement and formulate them as design ideas for both the artifact and the exercise process. A literature study and an interview study were carried out. This paper constitutes the basis for formulating the problem and outlining with design ideas for the project.

The results are based on literature that presents related research regarding managing wicked problems in exercises. The literature review was carried out using the key words; table top exercises, wicked, training, planning. No delimitation was made regarding research area so as to enable potentially include research from various fields. The empirical study is a pilot case in which I interviewed incident commander in a municipality in Norrbotten, Sweden, about their opinion of table top exercises. Four managers were interviewed: one each from the fire brigade, military services, health care, and a railway company. All had worked in their respective fields for many years and had extensive experience with exercises. Thematic semi-structured open-ended interviews were used [12]. The theme of the interviews was tabletop exercises and respondents were asked to comment on and suggest changes and improvements to exercises. The interviews were took place on six occasions. The theoretical description of tabletop exercises and the empirical data are analyzed through the lens of wicked problem. The findings are preliminary from the literature review. The interviews are mainly used as a contextual description for the problem and not the main focus of the paper.

\section{Wicked problems and Emergencies}

The concept of wicked problem has six characteristics: 1) The problem is not understood until after the formulation of a solution. 2) Wicked problems 
have no stopping rule. 3) Solutions to wicked problems are not right or wrong. 4) Every wicked problem is essentially novel and unique. 5) Every solution to a wicked problem is a "one shot operation." 6) Wicked problems have no given alternative solutions [10] [13]. I present the concept in more detail and illustrate it with examples from emergency situations.

1) The problem is not understood until after the formulation of a solution. The information needed to understand a problem is based on an idea of a possible solution. Solutions and an understanding of the problem are linked, but the solution to a wicked problem uncovers new problems that require further adjustment of the solution. This means that the problem must constantly be reformulated. It is only after a solution has been implemented that the effects can be evaluated and the problem understood. What the problem is depends on whom one asks. Different stakeholders hold different views and different opinions regarding an acceptable solution. Moreover, this type of problem often involves a large number of stakeholders [13] [10]. For example, in a forest fire many uncertain parameters lead to a problem that is difficult to define, and it is therefore difficult to know which operations (solutions) are required in order to manage the incident. Where did the accident occur? Are any people in danger, and if so, where are they located? What resources are available, and from whom and when are they available? What are the weather conditions now - and what will they be later on? In addition to emergency services, involved stakeholders may include landowners, property owners, nongovernmental organizations (NGOs), businesses, and the public. Another aspect is the conflicting interests of these stakeholders; the risk of conflicting interest increases as the number of participants in a rescue operation grows. Emergency services give first priority to saving lives and then turn to property. Private organizations affected by the potential loss of personnel or property have a vested interest in their employees and property in the first place. Emergencies are therefore often difficult to define and because they are difficult to define, coming up with solutions for the problems is likewise problematic [10].

2) Wicked problems have no stopping rule. Because the problem is not defined, it is not possible to set criteria that indicate when the problem has been resolved. Since there are infinite possible solutions to the problem, ending only when resources (in terms of time, money, etc.) are exhausted not because a definitive solution has been found [13] [10]. In, for example, forest fires, the action of firefighting stops once the fire will be extinguished cannot be predetermined. In the short run, stopping rules govern the response phase of emergencies (e.g., the forest fire has been extinguished), but in the long run, extending into the recovery phase, no stopping rule exist. We cannot tell when the damage the forest fire caused has been restored or the best way to restore it. Therefore, limiting the response phase is taming or simplifying the problem.

3) Solutions to wicked problems are not right or wrong. Solution quality cannot be determined objectively; rather stakeholders must assess it in terms of good, bad, or good enough [13] [10], and they can do so only in retrospect. In the case of a forest fire, the many landowners involved often have divergent opinions about the execution of the firefighting depending on the extent to which their properties have been affected.

4) Every wicked problem is essentially novel and unique. No two problems are identical, though there may numerous similarities. The solutions to these must always be tailored to the specific situation [13] [10]. It is very unlikely that more than one forest fire will start in the same geographical place and under the same weather conditions. Two forest fires may share certain characteristics such as strategies needed, but in terms of environmental factors they remain very different.

5) Every solution to a wicked problem is a "one shot operation." Each solution implemented will have consequences. Once a solution has been implemented a new context has been created, and the process of defining new wicked problems and possible solutions continues [13] [10]. As Conklin says "This is the "Catch 22" about wicked problems: you can't learn about the problem without trying solutions, but every solution you try is expensive and has lasting unintended consequences which are likely to spawn new wicked problems." [10]. Further, it is not possible to test a solution to see whether it works. Once an operation is decided on and efforts to extinguish the fire begin, no one can undo the operation. If the solution is ineffective, the new situation comprises another wicked problem to solve.

6) Wicked problems have no given alternative solutions. There may be no solutions, or there may be a number of possible solutions or a range of solutions that no one has yet considered. Designing potential solutions is a matter of creativity, and it is a matter of judgment to determine which are valid and should be completed and implemented [13] [10]. As long as the fire is not extinguished the problem must be reformulated depending on, for example, weather conditions. This means that forest fires may require innumerable possible operations aimed at resolving the problem.

Tame problems are the opposite of wicked ones; a tame problem has a well-defined and stable problem statement, a definite stopping point, a solution that can 
be objectively evaluated as right or wrong, solutions that can be tried and abandoned, further, it belongs to a class of similar problems that can be solved in a similar manner [13].

Large scale emergencies typically bear the characteristics of wicked problems while small-scale emergencies can more often be categorized as tame problems. Based on the definition of wicked problems and the characteristics of emergencies, I conclude that some problems that emergency managers face are wicked problems. A situation need not exhibit all the properties listed in order to be a wicked problem [10]. Fighting a forest fire, for instance, is a problem with both wicked and tame elements. I use the characteristics of wicked problems as a framework for analyzing tabletop exercises.

\section{Tabletop Exercises}

Exercise is the generic term for a range of activities that test emergency-response readiness, evaluate emergency-response plans, and assess the success of training and the development of plans. There is no authoritative definition of exercises, but they are usually categorized as either operation-based or discussion-based [18]. Operation-based exercises include drills, functional exercises, and full-scale exercises. They are used to test, train, practice, and assess plans, policies, agreements, and procedures. Discussion-based exercises include seminars, workshops, tabletop exercises, and games. Such exercises are used for training, practicing, assessing, and developing existing plans, policies, coordination, and procedures. Discussion-based exercises typically focus on strategic and policy-oriented issues, such as the coordination of agencies' operations during emergencies [18].

Tabletop exercises are discussion-based exercises used for training emergency managers. These exercises are used when multiple organizations need to collaborate on a managerial level - not only authorities specialized in responding to accidents (police, fire brigade, paramedics, etc.) but also organizations like private companies, NGOs, and military forces [14]. Participants may belong to a single group or agency or to a diverse range of agencies.

There are two types of tabletop exercises, basic and advanced [18]. A basic tabletop exercise is a facilitated analysis of an emergency situation in an informal, stress-free environment. It is designed to involve constructive discussion as participants examine and resolve problems based on existing operational plans and identify in what respect those plans should be refined. The purpose is to provide training and practice in coordination arrangements and to teach participants how all the elements fit together, as well as to improve the plans, if necessary. Equipment is not used, resources are not deployed, and time pressures are not introduced [18]. The activity is led by the exercise manager, who triggers the scenario by describing an emergency incident and makes sure that all key points are raised. The scenario remains constant during the exercise [18]. Information about the scenario takes the form of a prepared list of problems or events that is delivered on paper or through verbal requests, and each agency uses its own plans and its own approach to respond to and solve the problems [16]. Individuals may receive written problems and related discussion questions to answer from their own perspectives; these may then be discussed by the group. Improvements can be introduced to the plan if necessary [17]. Members of the different agencies are together in a single room. The exercise manager is also in the same room and in real time can follow and assess the way the scenario and the response develop [16].

An advanced tabletop exercise is a simulated interactive exercise that helps test an organization's capability of responding to a simulated event [18] [17]. It is a coordinated response to a situation in a timepressured, realistic simulation that involves several agencies. An advanced tabletop exercise focuses on the coordination, integration, and interaction of an organization's policies, procedures, roles, and responsibilities before, during, and after the simulated event. It heavily emphasizes communication among all the agencies participating in the exercise.

Members of the agencies gather in a coordination center. Exercise managers are in a separate area and run the game through paper feeds and phone or e-mail requests [16]. The information communicated to the participants is a sequence of "events," or prescripted messages, that describe the scenario. These messages can expand or alter the original scenario, and they may involve the consequences of earlier decisions and simulated reactions from the outside world. Participants are supposed to make decisions in real time in response to these messages [19]. If participants do not respond effectively, exercise managers can create new messages to force participants to act [19]. The exercise is carried out without any discussion, and there is no opportunity to start over after a failure because time is an important aspect of the activity [19].

In an advanced tabletop exercise, participants are grouped by organization or placed in functional groups (e.g., all police officers together) and separated from each other. The groups may use their own command center or contractor for support during the exercise [19]. 
There are variations on this exercise; it could involve an element of competition between groups, for instance. In such cases there is no interaction between the groups, and communication takes place only between a given group and the exercise manager. In another variation, all communication between the groups moves through the exercise manager, who monitors performance and group dynamics [16].

\section{The Pilot Case}

This study was carried out to gain insight into the native and to the current use of tabletop exercises. Most respondents held the opinion that their own organizations worked rather well in emergency responses but that improvements were needed in interorganizational coordination. The health care respondent pointed to a need for exercises focusing on internal coordination; this view stems from the fact that health care is divided into many specialized units that are geographically dispersed, and contact between them for dealing with accidents must be strengthened.

The respondents agreed that tabletop exercises are mostly used for practicing and drilling plans in their own organizations and that for this purpose, such exercises work well. As one respondent indicated, the goal of these activities is to "test plans, such as testing the evacuation of our control center." Tabletop exercises are used to validate and test a given organization's own plans but not to evaluate interorganizational coordination during the exercises. One respondent expressed a desire for additional tabletop exercises that would do this: "The usefulness of the exercises is too limited. I would like to have short interorganizational collaboration exercises where participants discuss shared problems that we face."

The exercises are rather predictable; one respondent commented, "I have participated in many exercises, and there is rarely anything new supplied. Most of the time, you practice what you already know." Another said, "You know how it is planned, and you know what will happen in the exercise." A third respondent believed that participants should prepare for the exercises and focus on certain areas: "Give homework with the action scenario. Identify the key events or decisions of the scenario to be addressed from an integrated perspective that can be discussed during the exercise."

The respondents concurred that a need exists for improved knowledge of other participants, contact people, available resources, expertise, plans, and so on. One suggested, "This can be done if participants in tabletop exercises are brought together in conversational discussions in an active way." This type of exercise could certainly support the development of personal relationships, given that the events often take place at conference facilities where participants can socialize before and after the exercise itself.

Another important aspect of exercises is the question who from each organization will participate particularly if plans and knowledge are to be developed during the exercises. "It is important that the right people participate in the exercises. [They should be at] a high enough level to be able to change the plans but at the right level to know the area." Feedback to the organization is another issue related to who is participating in the exercise. As one respondent expressed it, "In large part, only the participating members receive the knowledge."

\section{Design Ideas}

I propose three design ideas for designing tabletop exercises that better prepare emergency managers for wicked problems (table 1); these are based on the lens of wicked problems and practical issues raised in the empirical data.

\begin{tabular}{|c|c|}
\hline Design Ideas & Basis \\
\hline $\begin{array}{l}\text { First, focus on unsolved } \\
\text { (wicked) problems instead of } \\
\text { problems already handled in } \\
\text { plans and allow the participants } \\
\text { identify them. }\end{array}$ & $\begin{array}{l}\text { Wicked aspect 3, } 6 \\
\text { and empirical data }\end{array}$ \\
\hline $\begin{array}{l}\text { Second, let the participants } \\
\text { tame the problems when } \\
\text { solving them during the } \\
\text { exercise instead of taming } \\
\text { problems ahead of time when } \\
\text { planning the exercises. }\end{array}$ & $\begin{array}{l}\text { Wicked aspect } 1 \\
\text { and empirical data }\end{array}$ \\
\hline $\begin{array}{l}\text { Third, use existing plans and } \\
\text { lessons learned from previous } \\
\text { emergencies and resolve the } \\
\text { problems in collaboration. }\end{array}$ & $\begin{array}{l}\text { The concept of } \\
\text { muddling through } \\
\text { and the } \\
\text { collaborative } \\
\text { strategy }\end{array}$ \\
\hline
\end{tabular}

The first design idea is based on the third and the sixth aspects of wicked problems, as well as on evidence from the pilot case. The third aspect of wicked problems - solutions to wicked problems are not right or wrong - cannot be duplicated in tabletop exercises. This follows from the aforementioned fact that the instructor knows the problems and has solutions to them in mind. A further consideration is the focus on using plans to come up with solutions, as a result of which only problems that are expected or can be planned for are practiced. The instructor can also use messages to lead participants to act on specific events in a predetermined direction, which in some sense means that a solution exists. Emergencies that 
have workable plans cannot, by definition, be wicked; therefore, the focus should be on emergency scenarios that do not have plans - that is, on unsolved problems. The nonexistence of a plan does not render a problem wicked, but such problems nevertheless need to be practiced and properly handled. The sixth aspect of wicked problems - wicked problems have no given alternative solutions - cannot be incorporated into tabletop exercises as they are currently planned. Creating a situation in which participants are forced to be creative in order to find solutions and to use their judgment to select among solutions is simple if the problems are left unsolved, if there are no plans for the problems so that neither the participants nor the instructor has a predetermined solution in mind. Allowing participants, according to a given scenario, to identify unresolved issues is a proposal derived from the empirical data. It has to do with the predictability of exercises and answers the concern that participants often practice situations that they already know about. There must be a focus on unplanned problems if exercises are to train people to handle wicked problems. I also think that if participants are involved in identifying issues to address during the exercise, the predictability will decrease owing to the uncertainty regarding other participants' problems.

The second design idea stems from the first aspect of wicked problems and from the pilot case evidence. The first aspect of wickedness - the problem is not understood until after the formulation of a solution cannot be fully incorporated into tabletop exercises. The emergencies dealt with in tabletop exercises, what should be practiced, and what should be achieved with a specific exercise are all predetermined. There is a prepared list of problems or events that each participant is expected to respond to. Participants are supposed to use their own plans to act on the instructors' messages, but the use of plans to solve tasks during exercises is itself a limiting factor because plans cover only problems that can be anticipated. What about situations that cannot be planned for? Exercises need to handle these situations, as well. In their current form, tabletop exercises involve problems and solutions that are known in advance by the instructors and by the exercise developer. The empirical data show that participants often know in advance the purpose of the exercise, when and where the exercise will be implemented, and how long it will last. But wicked problems can by definition never be described or resolved fully; this means that problems have been tamed beforehand, during the planning of the exercise. In contrast, solving wicked problems is always about taming the problem. The question is who should tame the problem - the planner or the participant? I believe that the participant should tame the problem so as to learn how to act in a real situation.

The third design idea is derived from the approach of muddling through and from the collaborative approach to solving wicked problems. Since the emergency managers have experience with accidents, and given that the organizations they represent usually have plans for responding to accidents of various kinds, the muddling through approach seems an appropriate choice [8] [6]. Approaches for solving wicked problems are seen as a matter of teamwork and as a social phenomenon [10] [20]; therefore, I believe that a collaborative approach [9] is suitable when designing tabletop exercises to focus on managing wicked problems. There is time to handle problems in the preparation phase, as there is not in the response phase, a fact that also supports the choice of a collaborative strategy. There must be some strategy for managing such problems, and learning how to use these strategies is one part of dealing with wicked problems.

I have not used wicked aspects 2, 4, and 5 to develop the design ideas. The second aspect of wickedness - wicked problems have no stopping rule is not addressed in tabletop exercises. This aspect has not been used for developing the design ideas because it depends on simplifying or taming the problem and is therefore limited to only the response phase. The response phase has two overall objectives: first rescue people, then save property. The goal is achieved when the fire is extinguished or when injured people are transported to hospitals, whether the problems have been solved in a good or bad way.

The forth aspect of wickedness - every wicked problem is essentially novel and unique - can be reproduced in tabletop exercises because it is always possible to create new scenarios with new conditions. Therefore, this aspect has not been used for developing the design ideas. The same type of accident, such as a train accident, can be used several times since it is possible to change the conditions, such as the seasons, weather, geographic location, type of train, and so on.

It is also possible to handle the fifth aspect of wickedness - every solution to a wicked problem is a "one-shot operation" - in tabletop exercises. This aspect focuses on the fact that the actions taken cannot be undone and will create a new context and new problems to solve. The accident in the exercise scenario can be constructed so that no participants can establish in advance criteria for when and how the task will end; thus, the process of reformulating the problem persists, and participants must develop new solutions to each new aspect of the problem. This kind of change requires improvisation from the instructor 
because it is difficult or impossible to plan for all the decisions that might be made.

\section{Discussion}

Findings in this article shows that tabletop exercises do not accurately reflect the reality of wicked problems and suggests three design ideas that would better prepare emergency managers to address real wicked problems. From the results, I conclude that tabletop exercises partly mirror wicked problems but cannot incorporate every aspect of such situations. The concept of wicked problems itself identifies two main reasons for this. First, planning tabletop exercises in which the problems and solutions are known ahead of time tames the problems. Second, focusing on the use of plans entails neglecting unplanned problems, and some of these unaddressed problems may be wicked. The planning of tabletop exercises must therefore be changed to include problems with wicked aspects. Exercises involving problems with wicked aspects can also be adapted to practice managing tame problems. Wicked problems must be tamed before they can be solved, which means that even an exercise that starts with a wicked problem eventually addresses a more or less tamed problem. The challenge with wicked problems is to tame or limit them so that they can then be resolved.

The proposed design ideas for better managing wicked problems focus on this issue. The first design idea suggests that the focus should be on unsolved problems that the participants themselves come up with. This implies that exercises should not be planned as a sequence of predetermined events responded to according to a plan, since no one will have outlined plans or solutions to these problems in advance. The second design idea suggests that problems should be tamed during the exercise by the participants instead of during the planning phase by the developer. Thus, the planning of tabletop exercises should be modified to focus more on problems than on solutions. The third design idea focuses on how to deal with wicked problems by using existing plans and lessons learned from previous emergencies so as to solve problems in collaboration. This idea is best suited for the basic exercise type because that is the type used more for training and planning, it can incorporate discussions, and it does not involve the same time pressure as the advanced type.

The intention of this work was to define design ideas as a foundation for developing an Internet-based tool for tabletop exercises, but the ideas outlined can also be used by practitioners to complement traditional tabletop exercises. The suggested design ideas should be seen as complementing existing exercises and not replacing them, because it will always be necessary to test plans in the way that most exercises currently do.

Further research should implement the suggested design ideas in an artifact and then evaluate the way they improve tabletop exercises in terms of coping more effectively with wicked problems. This could be done either by developing an Internet-based tool or by using exercises in the traditional way. Future studies could also investigate the way exercises are used in the recovery phase and whether the suggested design ideas are useful in that setting.

\section{References}

[1] N.C. Simpson, and P. G. Hancock, "The incident commander's problem: resource allocation in the context of emergency response" International Journal of Services Sciences, Volume 2, Number 2, 2009, pp. 102 - 124.

[2] C. Stubbart, Uncertainty, "Complexity, Conflicts of Interest, Emotional Involvement, and the Quality of Crisis Thinking" Faculty Working Paper No 1289 College of Commerce and Business Administration University of Illinois at Urbana-Champaign

http://www.archive.org/details/uncertaintycompl1289stub

[3] W.P Perry and M.K. Lindell, "Preparedness for Emergency Response: Guidelines for the Emergency Planning Process" Disasters, 27(4), 2003, pp. 336-350.

[4] J. Dowell, "Tabletop Crisis Training and the Requirements for Computer-Based Simulators" Journal of Intelligent Systems, 1995, Vol. 5 Nos., pp. 2-4.

[5] M.Turoff, C. White, L. Plotnick, and S.R. Hiltz, "Dynamic Emergency Response Management for Large Scale Decision Making in Extreme Events", Proceedings of the 5th International ISCRAM Conference - Washington DC, USA, 2008.

[6] C.E. Lindblom, "The Science of Muddling Through", Public Administration Review, 1959, pp. 79-88.

[7] G. O'Brien, P. O'Keefe, Z. Gadema, and J. Swords, "Approaching disaster management through social learning", Disaster Prevention and Management, Vol. 19 No. 4, 2009, pp. 498-508.

[8] L. Plotnick, M. Turoff, G.Van Den Eede, "Reexamining Threat Rigidity: Implications for Design", Proceedings of the 42nd Hawaii International Conference on System Sciences, 2009

[9] N. Roberts, "Wicked Problems and Network Approaches to Resolution", International Public Management Review, electronic Journal at http://www.ipmr.net, Volume 1, Issue 1, 2000, pp. $1-19$ 
[10] J. Conklin, "Dialogue Mapping: Building Shared Understanding of Wicked Problems" John Wiley \& Sons, West Sussex, England, 2006.

[11] A.R. Hevner, S.T. March, J. Park, and S. Ram, "Design Science in Information Systems Research", MIS Quarterly, Vol.28 No. 1, 2004, pp. 75-105.

[12] M.D. Myers, M. Newman, "The qualitative interview in IS research: Examining the craft", Elsevier Ltd. Information and Organization 17, 2007, pp. 2-26.

[13] H.W.J Rittel, and M.M. Webber, "Dilemmas in a General Theory of Planning", Policy Science 4, 1973, pp. 155-169.

[14] C.F. Payne, "Contingency plan exercises", Disaster Prevention and Management. Volume 8, Number 2, 1999, pp. 111-117.

[15] D.M. Peterson, and R.W. Perry, "The impacts of disaster exercises on participants", Disaster Prevention and Management, Volume 8, Number 4, 1999, pp. 241-254.

[16] B. Overy, "The different types of exercise: when to use them", Paper presented at the 5th Disaster Prevention and Limitation Conference, Bradford, 1993.
[17] S. Renner, "Emergency Exercise and Training Techniques", Australian Journal of Emergency Management, Vol. 16, No. 2, 2001, pp. 26 - 35.

[18] Homeland Security Exercise and Evaluation Program (HSEEP) Volume II: Exercise Planning and Conduct, https://hseep.dhs.gov/support/volumeii.pdf

[19] Öva krishantering, Publication number: MSB 0063-09, https://www.msb.se/sv/Produkter--

tjanster/Publikationer/Publikationer-fran-MSB/Ovakrishantering/

[20] R.W. Huthinson, S.L. English, and M. Mughal, (2002) "A General Problem Solving Approach for Wicked Problems: Theory and Application to Chemical Weapons Verification and Biological Terrorism", Group Decision and Negotiation 11, Kluwer Academic Publishers. Netherlands, 2002, pp. 257-279.

[21] M. Turoff, S.R. Hiltz, C. White, A. Hendela, and X.Yao, "The Past as the Future of Emergency Preparedness and Management", International Journal of Information Systems for Crisis Response (IJISCRAM), 1, 1, in press. 